\title{
Prevalence of HPV and pathological changes among women 70 years of age, 10 years after exclusion from the Swedish cervical cancer screening program
}

\author{
Lovisa Bergengren ${ }^{1}\left[\right.$ [ Mats G. Karlsson ${ }^{2} \cdot$ Gisela Helenius $^{2}$
}

Received: 23 August 2019 / Accepted: 10 February 2020 / Published online: 19 February 2020

(c) The Author(s) 2020

\begin{abstract}
Purpose Örebro County introduced an updated screening program 2016 with primary HPV test for women over 30 years and prolonged screening, increasing the cut-off age from 56-60 to 64-70. The aim of this study was to investigate the prevalence of HPV genotypes and their correlation to histological changes in women, 10 years after exclusion from the screening program, due to an eventual implementation of a catch-up program including all women aged 60-70.

Methods All women in Örebro County, born 1,946 $(n=1,968)$, were invited to a liquid-based cell sample with primary HPV screening. Samples were analyzed for hrHPV mRNA and positive samples were genotyped. hrHPV positive women were offered to do a conization.

Results Out of 809 participants, 31 (3.8\%) were hrHPV positive, of these 22 did a conization. Histologically, 5/22 (23\%) had LSIL and 5/22 (23\%) had HSIL. Normal histology was found in 12/22 (55\%). The most prevalent genotypes were HPV 16, $33,52,56$, and 68 . Of the women with HSIL, one case of cervical cancer was confirmed in a recone biopsy after 4 months. Conclusion The study showed considerable prevalence of hrHPV and histologically confirmed LSIL/HSIL. These data led to catch-up screening for women between 60 and 70 years when overlapping two screening strategies.
\end{abstract}

Keywords HPV prevalence $\cdot$ Cervical cancer $\cdot$ Screening $\cdot$ HPV genotypes $\cdot$ Older women

\section{Introduction}

The prevalence of infection with oncogenic types of human papillomavirus (HPV) and cervical dysplasia in women of 60 years of age and older, has not been extensively studied. A prevalence of 5.5\% of high-risk HPV (hrHPV) has been reported for our region [1]. Different studies, all with quite small numbers, show similar prevalence figures, $8 \%$ in a Danish study among women $>65$ [2], 5\% in the Athena trial among 70-year-old women or older [3], and also 5\% in an Australian study [4].

Systematic cervical cancer screening has led to a significant decrease in cervical cancer cases in Sweden $[5,6]$, as

Lovisa Bergengren

lovisa.bergengren@regionorebrolan.se

1 Deparment of Women's Health, Faculty of Medicine and Health, Örebro University, 70185 Örebro, Sweden

2 Deparment of Laboratory Medicine, Faculty of Medicine and Health, Örebro University, 70185 Örebro, Sweden well as worldwide [7]. However, the incidence has increased in recent years in Sweden with around 100 cases per year and in 2017, 559 new cases of cervical cancer were diagnosed in Sweden, and 149 died of the disease [8]. About $30 \%$ of the cases of cervical cancer occur in women older than 60 and the mortality rate is around $70 \%$ in this age group $[9,10]$.

The current screening policy that uses primary HPV screening in the ages 30-64, and samples only analyzed with cytology as a triage if found hrHPV positive, was issued in 2015 by the National Board of Health and Welfare [11]. Implementation of the new policy is ongoing, but is not yet nationwide. Recommended from 30 years is primary HPV screening, whereas cytology as primary screening continues between 23 and 29 years. This is a recommended regime from both WHO, EU, and the Swedish National Board of Health and Welfare since persistent hrHPV infection is a prerequisite for development of precancerous lesions as well as manifest cervical cancer $[12,13]$. The new recommendation includes women up to 64 years of age, and recommend screening tests every third year from 23 to 49 , and 
every seventh year 50-64 years of age. With a last sample after turning 64 , some women will be 70 years of age at last screening round.

The shift to a new screening strategy demands resources as well as several organizational changes in both the clinic and the laboratory. The screening algorithm with screening up to 60 years of age was interpreted as stopping at 60 . This has led to a group of women that have not been tested since 55-60 years of age, which is a considerable difference from a last sample at 64-70. In Örebro County, HPV as primary screening has been offered since September 2016. Challenges with a group of women in between two screening strategies occurred at this point. Cost, effectiveness, and the capacity to include all these women who were not screened with HPV nor cytology for 10-14 years, were taken under consideration. The reduction of cervical cancer in countries with an existing cervical screening program is mainly among women in age 30-60 years and not to the same extent among women above this age cohort $[6,14]$. Data show that over $60 \%$ of the newly diagnosed cervical cancers in Sweden are found among women over 65 years of age and/or women who have not participated in the screening program for the last 7 years $[15,16]$.

The aim of the study was to distinguish the prevalence of HPV and the relations to histological findings among women of 70 years of age, at least 10 years after inclusion in a former cervical cancer screening program. The result of this study was useful in making legitimate decisions on how to implement HPV-based screening program and invitations for older women in Örebro County.

\section{Materials and methods}

\section{Study population}

All women born 1946 in Örebro County, were invited by letter April 2016 to April 2017, $n=1968$. These women were no longer included in the organized screening program for cervical cancer and exited the program at least 10 years ago. The invitation contained an offer about professional screening for cervical cancer, sampled by midwives at Örebro University hospital. All women who had undergone a hysterectomy $(n=204)$ were excluded and all non-responders after a first invitation, were reminded by a new invitation. Informed consent was obtained from all individual participants included in the study. The Regional Ethical Review Board, Uppsala, Sweden, approved this study (Dnr 2014/121).

\section{HPV screening and genotyping}

Samples were collected using liquid-based cytology (LBC) (ThinPrep, Hologic, Marlborough, MA, USA). The samples were collected from May 2016 to May 2017. All samples were analyzed with Aptima HPV Assay (Hologic, Marlborough, MA, USA) which is a qualitative nucleic acid amplification test that detects HPV E6/E7 mRNA from 14 high-risk HPV types (16, 18, 31, 33, 35, 39, 45, 51, 52, 56, 58, 59, 66 , and 68) in LBC samples. The test results in hrHPV positive or negative without discrimination between genotypes. Therefore, samples positive for any of the $14 \mathrm{hrHPV}$ were subjected to DNA extraction and genotyping with multiplex real time PCR test Anyplex ${ }^{\mathrm{TM}}$ II HPV28 (Seegene, Seoul, Korea).

\section{Cytology}

All hrHPV positive LBC specimens were screened by one certified cytotechnician and assessment followed the international Bethesda classification system with atypical squamous cells of undetermined significance (ASC-US), atypical squamous cells, cannot exclude high-grade lesion (ASC-H), low-grade squamous intraepithelial lesion (LSIL), highgrade squamous intraepithelial lesion (HSIL), squamous cell carcinoma, atypical glandular cells (AGC), adenocarcinoma in situ (AIS), or adenocarcinoma.

\section{Cone biopsy and histology}

The women with samples positive for hrHPV mRNA were offered an appointment to a senior gynecologist (author LB) for electrosurgical cone biopsy, in local anesthesia.

The cone specimens were formalin-fixed, paraffin-embedded and sections $(4 \mu \mathrm{m})$ were stained with hematoxylin and eosin and evaluated according to current WHO classification [17], by one senior pathologist. The last follow-up sample in the study was 6 months after the cone biopsy. If the women had findings, clinical follow-up continued as the national screening program stipulated [18].

\section{Results}

Of the 1968 women that were invited to this study, 809 accepted to participate. 204 were excluded after invitation due to a previous hysterectomy $(10 \%)$ and the rest were nonresponders (Fig. 1).

When analyzing the LBC samples, hrHPV positivity was seen in $31 / 809$ specimens, a prevalence of $3.8 \%$. Among the hrHPV positive samples, $2 / 31(7 \%)$ were negative with the DNA-based genotyping test. The most common HPV genotypes were HPV 16, 33 and 68 , with a prevalence of $0.6 \%$ each for the whole study population (Fig. 1a). Samples positive for more than one genotype were seen in $7 / 31$ (23\%), and several HPV genotypes were only positive in multi-infections, 35, 45, 51, 53, 59, 66, and 73 . 
a

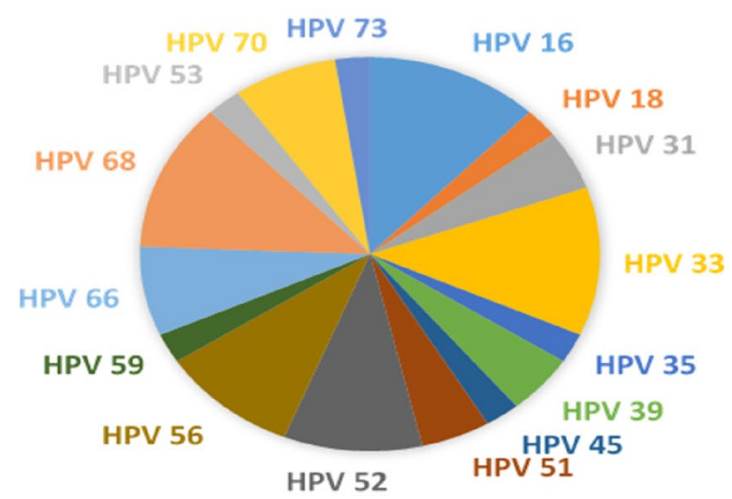

b

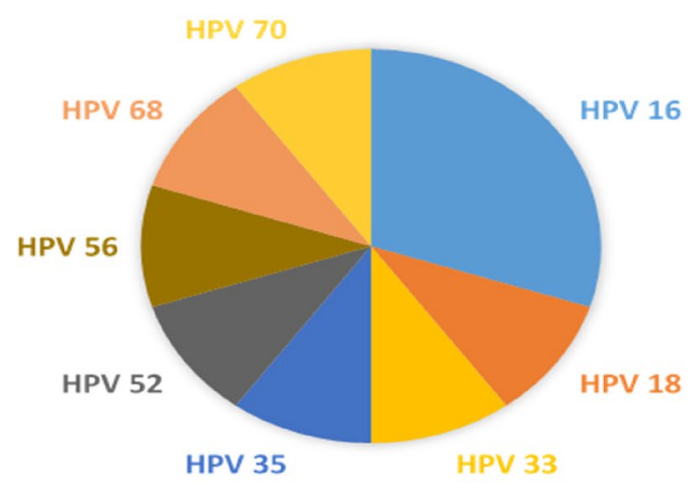

c

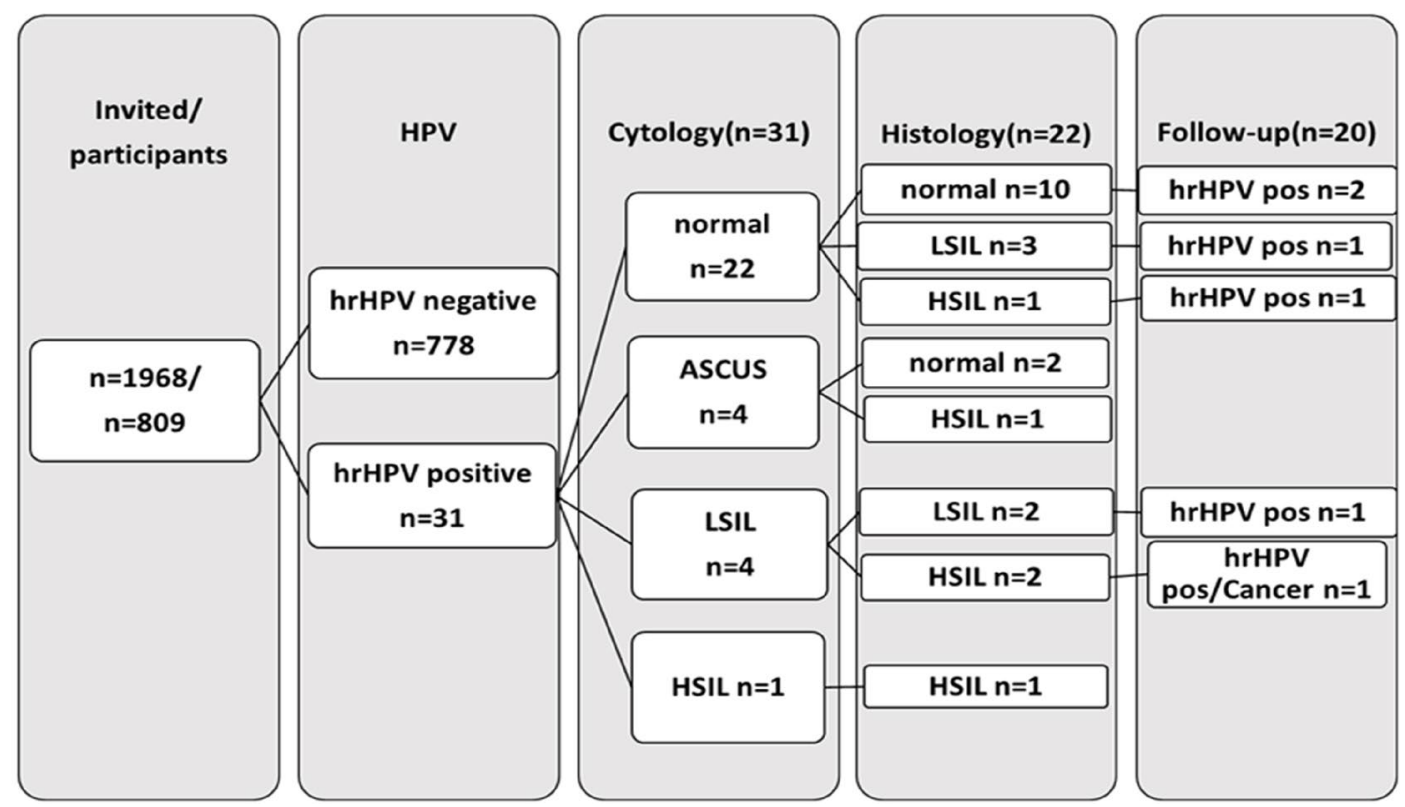

Fig. 1 a Distribution of genotypes in all positive samples, $\mathbf{b}$ distribution of genotypes in samples with dysplasia, $\mathbf{c}$ flow chart of HPV, cytology, and dysplasia occurrence

All hrHPV-positive samples were analyzed with cytology and 9 (29\%) had cytological abnormality, 4 (13\%) with ASCUS, 4 (13\%) LSIL and 1 (3\%)with HSIL (Fig. 1c). These women either accepted to do a cone biopsy or were followed according to the current guidelines at the time when carrying through with the study [18].

Of the women with hrHPV positive test results, 22/31 (71\%) did a cone biopsy, and of these 10/22 (45\%) had histological abnormalities on examination, 5 LSIL and 5 HSIL. Of these 10 dysplasias, 6 had aberrant cytology on earlier LBC specimens (Fig. 1c).

After the conization, a new screening sample was taken on all women 4-6 months after the cone and results showed that $6 / 20$ women still had hrHPV positive samples. One of the HSIL was found to be squamous cell carcinoma IA at follow-up after 4 months, and proceeded to surgery as stipulated per guidelines (Fig. 1).

\section{Discussion}

HPV-based screening has the potential to prevent additional cases of cervical cancer in women over 65 years of age. However, the clinical management of HPV positivity in older age groups is not well established. In this study, the prevalence of histological verified dysplasia among the 70 -year-old women with positive hrHPV was $45 \%$. This is high, considering that during the same time interval, in the same county, $36 \%$ of 50 -year-old women with screening samples showing either LSIL or hrHPV had histological 
verified dysplasia, 3 LSIL, and 1 HSIL (data from local registries).

The prevalence of hrHPV in our study population was $3.8 \%$, which is in good agreement with another Swedish study where $4.1 \%$ of the women (mean age 68 ) were hrHPV positive [19]. Different studies show a prevalence that differ worldwide. Among European studies, HPV prevalence among women between 55 and 65 differ from just below 5\% to just over $10 \%$, but data from 70 -year-old women are to our knowledge lacking [2, 20-23]. The difference in HPV prevalence may be due to if an organized screening program is in practice, as well as a how frequent women undergo hysterectomy in a population.

The number of hysterectomised women in this cohort was $10 \%$ (204 of 1,968 responding to the study). This is consistent with other studies for example in Denmark, where 11.9\% of women of 55-64 years had done surgery [24], whilst another Danish study showed a prevalence of hysterectomy among women above 65 to be $\geq 16 \%$ [25]. Both studies were focusing on attendance rate in the screening program. The exact number of hysterectomised women among the nonresponders to this study is unknown though.

In Örebro County, Sweden, there has been an organized screening program in place since the 1960 s, which means that the study population can be considered well screened. During the years 2003-2005, this age cohort had a screening attendance rate of around $87-89 \%$. This may explain our rather low prevalence results. In this study, there is no information about whether the participants are the women that actually have participated regularly in the screening program, nor if they had normal screening results between 50-60 years of age.

Data from Wang et al. [14] show the importance of screening up to older ages, if the woman has abnormal screening history or is unscreened with cytology or HPV [26]. This fact, together with the results showing that almost half of the hrHPV positive women had dysplasia indicates even more obviously the advantages of including all women up to 70 years of age, when switching to primary HPV screening strategy. Evidence also show that there is lower performance of cervical cytology as a screening tool in this particular population [27]. This together with the fact that hrHPV is a necessary cause of cervical cancer [12] prove that all women should now be included in the new screening program based on hrHPV before exclusion from the screening program.

We also strongly advise conization directly after a positive hrHPV together with LSIL on cytology, for women who have not attended the screening program for a long time, 10 years or more. In addition, a cone biopsy is suggested regardless of cytology results on only one hrHPV positive test if the woman is older than 64 and HPV status is unknown for many years, since our data show $45 \%$ dysplasia rate. This is in consistence with data from Elfgren et al. [28] as their results show evidence of very high long-term risk of HSIL among women with continuous HPV persistence, as well as data on HPV infection, which more often tend to become persistent in menopausal women [22].

The strength of this study is that the study population equals the target group in case that the health care organization makes a decision to perform a catch-up screening program. The limitations of the study are the small study group and low take-up, $46 \%$, as well as the fact that there could not be a control group. The screening coverage in this region in Sweden among women aged 51-60 has been around 70-75\% for several years, and further back even higher, and the general impression is that women generally are interested in being screened.

The prevalence of hrHPV and the high proportion of histological occurrences in the biopsies (45\%) in this study, also including diagnosis of an early cancer, urged the County Council to extend the screening program to include all women up to 70 years of age, regardless of screening tests that were taken before the implementation. This catch-up program will be evaluated and reported, to get more data on HPV prevalence among women between $60-70$ years of age. Since to our knowledge, evidence about this transition phase between two methods are not well analyzed, and since Örebro County, in the Swedish context, was early in changing to HPV screening strategies, this study can be of great value clinically and for local screening organizations. Almost all countries with organized screening are now considering transition to primary HPV testing, if it is not already completed.

Acknowledgments Open access funding provided by Örebro University. The authors would like to thank midwifes in Region Örebro County, cytotechnician Jessica Lantz, Malin Kaliff M.Sc. for laboratory work, Louisa Dorofte M.D. for histopathological assessments and Lars Breimer M.D, Ph.D for linguistic revision.

Funding Region Örebro County Research Committee and Örebro University Hospital Research Foundation (Grant Nos. OLL-576341, OLL-616292, OLL-639751, OLL-811061) funded the present study.

\section{Compliance with ethical standards}

Conflict of interest The authors declare that they have no conflict of interest.

Open Access This article is licensed under a Creative Commons Attribution 4.0 International License, which permits use, sharing, adaptation, distribution and reproduction in any medium or format, as long as you give appropriate credit to the original author(s) and the source, provide a link to the Creative Commons licence, and indicate if changes were made. The images or other third party material in this article are included in the article's Creative Commons licence, unless indicated otherwise in a credit line to the material. If material is not included in the article's Creative Commons licence and your intended use is not permitted by statutory regulation or exceeds the permitted use, you will 
need to obtain permission directly from the copyright holder. To view a copy of this licence, visit http://creativecommons.org/licenses/by/4.0/.

\section{References}

1. Bergengren L, Lillsunde-Larsson G, Helenius G, Karlsson MG (2019) HPV-based screening for cervical cancer among women 55-59 years of age. PLoS ONE 14(6):e0217108. https://doi. org/10.1371/journal.pone.0217108

2. Bonde J, Rebolj M, Ejegod DM, Preisler S, Lynge E, Rygaard C (2014) HPV prevalence and genotype distribution in a populationbased split-sample study of well-screened women using CLART HPV2 human papillomavirus genotype microarray system. BMC Infect Dis 14:413. https://doi.org/10.1186/1471-2334-14-413

3. Wright TC Jr, Stoler MH, Behrens CM, Apple R, Derion T, Wright TL (2012) The ATHENA human papillomavirus study: design, methods, and baseline results. Am J Obstet Gynecol. 206(1):46.e1-46.e11. https://doi.org/10.1016/j.ajog.2011.07.024

4. Brotherton JM, Hawkes D, Sultana F, Malloy MJ, Machalek DA, Smith MA et al (2019) Age-specific HPV prevalence among 116,052 women in Australia's renewed cervical screening program: a new tool for monitoring vaccine impact. Vaccine 37(3):412-416. https://doi.org/10.1016/j.vaccine.2018.11.075

5. Bergstrom R, Sparen P, Adami HO (1999) Trends in cancer of the cervix uteri in Sweden following cytological screening. Br J Cancer 81(1):159-166. https://doi.org/10.1038/sj.bjc.6690666

6. Vaccarella S, Franceschi S, Engholm G, Lonnberg S, Khan S, Bray F (2014) 50 years of screening in the Nordic countries: quantifying the effects on cervical cancer incidence. $\mathrm{Br} \mathrm{J}$ Cancer 111(5):965-969. https://doi.org/10.1038/bjc.2014.362

7. Gustafsson L, Ponten J, Bergstrom R, Adami HO (1997) International incidence rates of invasive cervical cancer before cytological screening. Int J Cancer 71(2):159-165

8. Welfare TNBoHa. Socialstyrelsen (2019) https://www.socialstyr elsen.se/statistik/statistikdatabas/cancer. Accessed 27 May 2019

9. Welfare TNBoHa. Statistikdatabas dödsorsaker: The National Board of Health and Welfare (2018) https://www.socialstyrelsen .se/statistik/statistikdatabas/dodsorsaker. Accessed 2018

10. Lonnberg S, Anttila A, Luostarinen T, Nieminen P (2012) Agespecific effectiveness of the Finnish cervical cancer screening programme. Cancer Epidemiol Biomarkers Prev 21(8):1354-1361. https://doi.org/10.1158/1055-9965.epi-12-0162

11. Socialstyrelsen. Screening för livmoderhalscancer - Rekommendation och bedomningsunderlag. Artikelnr 2015-6-39. https:// www.socialstyrelsen.se/Lists/Artikelkatalog/Attachments/19873 12015-6-39.pdf. Accessed june 2015

12. zur Hausen $H$ (2009) Papillomaviruses in the causation of human cancers-a brief historical account. Virology 384(2):260-265. https://doi.org/10.1016/j.virol.2008.11.046

13. Walboomers JM, Jacobs MV, Manos MM, Bosch FX, Kummer JA, Shah KV et al (1999) Human papillomavirus is a necessary cause of invasive cervical cancer worldwide. J Pathol 189(1):12-19. https://doi.org/10.1002/(sici)1096-9896(199909)189:1\%3c12:aidpath431\%3e3.0.co;2-f

14. Wang J, Andrae B, Sundstrom K, Ploner A, Strom P, Elfstrom $\mathrm{KM}$ et al (2017) Effectiveness of cervical screening after age 60 years according to screening history: nationwide cohort study in Sweden. PLoS Med 14(10):e1002414. https://doi.org/10.1371/ journal.pmed.1002414

15. Darlin L, Borgfeldt C, Widen E, Kannisto P (2014) Elderly women above screening age diagnosed with cervical cancer have a worse prognosis. Anticancer Res 34(9):5147-5151
16. Andrae B, Kemetli L, Sparen P, Silfverdal L, Strander B, Ryd W et al (2008) Screening-preventable cervical cancer risks: evidence from a nationwide audit in Sweden. J Natl Cancer Inst 100(9):622-629. https://doi.org/10.1093/jnci/djn099

17. World Health Organization, International Agency for Research on Cancer (2014) WHO Classification of Tumours of Female Reproductive Organs [Elektronisk resurs]. International Agency for Research on Cancer, Lyon

18. cervixcancerprevention Sffooga-orf. Cervixcancerprevention 2010. https://www.sfog.se/natupplaga/nr6393f53d8d-2b98-4cdfa05a-aca202db2496.pdf. Accessed 7 Jan 2020

19. Hermansson RS, Olovsson M, Hoxell E, Lindstrom AK (2018) HPV prevalence and HPV-related dysplasia in elderly women. PLoS ONE 13(1):e0189300. https://doi.org/10.1371/journ al.pone. 0189300

20. Lamin H, Eklund C, Elfstrom KM, Carlsten-Thor A, Hortlund M, Elfgren K et al (2017) Randomised healthcare policy evaluation of organised primary human papillomavirus screening of women aged 56-60. BMJ Open 7(5):e014788. https://doi.org/10.1136/ bmjopen-2016-014788

21. Asciutto KC, Forslund O, Borgfeldt C (2018) Prevalence of high-risk HPV in postmenopausal women with benign cervical cytology-a population-based cohort study. Anticancer Res 38(7):4221-4228. https://doi.org/10.21873/anticanres.12718

22. Tifaoui N, Maudelonde T, Combecal J, Vallo R, Doutre S, Didelot MN et al (2018) High-risk HPV detection and associated cervical lesions in a population of French menopausal women. J Clin Virol 108:12-18. https://doi.org/10.1016/j.jcv.2018.08.010

23. Brogaard KA, Munk C, Iftner T, Frederiksen K, Kjaer SK (2014) Detection of oncogenic genital human papillomavirus (HPV) among HPV negative older and younger women after 7 years of follow-up. J Med Virol 86(6):975-982. https://doi.org/10.1002/ jmv. 23914

24. Larsen MB, Mikkelsen EM, Jeppesen U, Svanholm H, Andersen B (2017) The influence of total hysterectomy in a cervical cancer screening population: a register-based cross-sectional study. BMC Health Serv Res 17(1):423. https://doi.org/10.1186/s1291 3-017-2371-4

25. Lam JU, Lynge E, Njor SH, Rebolj M (2015) Hysterectomy and its impact on the calculated incidence of cervical cancer and screening coverage in Denmark. Acta Oncol 54(8):1136-1143. https:// doi.org/10.3109/0284186x.2015.1016625

26. Castañón A, Landy R, Cuzick J, Sasieni P (2014) Cervical screening at age 50-64 years and the risk of cervical cancer at age 65 years and older: population-based case control study. PLoS Med. https://doi.org/10.1371/journal.pmed.1001585

27. Gustafsson L, Sparen P, Gustafsson M, Pettersson B, Wilander E, Bergstrom R et al (1995) Low efficiency of cytologic screening for cancer in situ of the cervix in older women. Int $\mathrm{J}$ Cancer 63(6):804-809

28. Elfgren K, Elfstrom KM, Naucler P, Arnheim-Dahlstrom L, Dillner J (2017) Management of women with human papillomavirus persistence: long-term follow-up of a randomized clinical trial. Am J Obstet Gynecol 216(3):264.e1-264.e7. https://doi. org/10.1016/j.ajog.2016.10.042

Publisher's Note Springer Nature remains neutral with regard to jurisdictional claims in published maps and institutional affiliations. 